\title{
Salt Reduction Strategies in Portuguese School Meals, from Pre-School to Secondary Education-The Eat Mediterranean Program
}

\author{
Ana Isabel Rito ${ }^{1,2, *(\mathbb{D})}$, Sofia Mendes ${ }^{2,3}$, Mariana Santos 1,3 , Francisco Goiana-da-Silva ${ }^{4}$, \\ Francesco Paolo Cappuccio ${ }^{5} \mathbb{D}$, Stephen Whiting ${ }^{6}$, Ana Dinis ${ }^{7}$, Carla Rascôa ${ }^{7}$, \\ Isabel Castanheira ${ }^{1}$, Ara Darzi ${ }^{4}$ and João Breda ${ }^{6}$ (iD) \\ 1 WHO Collaborating Centre on Nutrition and Childhood Obesity-National Institute of Health Dr. Ricardo \\ Jorge (INSA, IP), 1649-016 Lisbon, Portugal; Mariana.Coelho@insa.min-saude.pt (M.S.); \\ isabel.castanheira@insa.min-saude.pt (I.C.) \\ 2 Centre for Studies and Research in Social Dynamics and Health (CEIDSS), 1649-016 Lisbon, Portugal; \\ sofiamendes@ceidss.com \\ 3 National School of Public Health, NOVA University of Lisbon, 1600-560 Lisbon, Portugal \\ 4 Centre for Health Policy, Institute of Global Health Innovation, Imperial College London, London SW7 2AZ, \\ UK; franciscogoianasilva@gmail.com (F.G.-d.-S.); a.darzi@imperial.ac.uk (A.D.) \\ 5 University of Warwick, WHO Collaborating Centre for Nutrition, Warwick Medical School, \\ Coventry CV2 2DX, UK; f.p.cappuccio@warwick.ac.uk \\ 6 WHO European Office for the Prevention and Control of Noncommunicable Diseases, \\ 125009 Moscow, Russia; whitings@who.int (S.W.); rodriguesdasilvabred@who.int (J.B.) \\ 7 Regional Health Administration of Lisbon and Tagus Valley (ARSLVT), 1700-179 Lisbon, Portugal; \\ ana.dinis@arslvt.min-saude.pt (A.D.); carla.rascoa@arslvt.min-saude.pt (C.R.) \\ * Correspondence: ana.rito@insa.min-saude.pt; Tel.: +351-217-519-200
}

Received: 23 June 2020; Accepted: 16 July 2020; Published: 24 July 2020

\begin{abstract}
High sodium (salt) consumption is associated with an increased risk of developing non-communicable diseases. However, in most European countries, Portugal included, sodium intake is still high. This study aimed to assess the sodium content of school meals before and after the Eat Mediterranean (EM) intervention-a community-based program to identify and correct nutritional deviations through the implementation of new school menus and through schools' food handlers training. EM (2015-2017) was developed in 25 schools (pre to secondary education) of two Portuguese Municipalities, reaching students aged 3-21 years old. Samples of the complete meals (soup + main course + bread) from all schools were collected, and nutritional quality and laboratory analysis were performed to determine their nutritional composition, including sodium content. Overall, there was a significant decrease $(-23 \%)$ in the mean sodium content of the complete school meals, which was mainly achieved by the significant reduction of $34 \%$ of sodium content per serving portion of soup. In conclusion, EM had a positive effect on the improvement of the school meals' sodium content, among the participant schools. Furthermore, school setting might be ideal for nutrition literacy interventions among children, for flavors shaping, and for educating towards less salty food acceptance.
\end{abstract}

Keywords: community-based program; childhood obesity; school meals; salt intake; sodium consumption

\section{Introduction}

Given the well-established evidence that excessive sodium consumption ( $1 \mathrm{~g}$ of sodium per $100 \mathrm{~g}$ represents $2.5 \mathrm{~g}$ of salt per $100 \mathrm{~g}$ ) is linked to an increased risk of developing non-communicable diseases (NCD) [1], a reduction in population's sodium consumption has been a key focus of both the 
international and national policy agendas. Reducing salt intake in the general population is not only a practical action that can prevent adverse health outcomes-such as increased blood pressure-but it is also a feasible and cost-effective strategy to reduce the growing burden of NCDs and reduce health-care costs for governments and individuals [2].

The World Health Organization (WHO) recommends a population reduction in salt intake as one of the 'best buys' or cost-effective actions that should be prioritized to tackle the global burden of NCDs [3-5]. Targets of a daily salt intake lower than $5 \mathrm{~g}$ for adults and $2 \mathrm{~g}$ for children have been recommended [6]. In addition, WHO Member States have agreed to work towards the global target of a 30\% relative reduction in mean population intake of salt by 2025 relative to 2010 levels. It is crucial that this target is met in order to achieve the overall goal of a $25 \%$ reduction in premature mortality from NCDs by 2025 [2].

The overall number of countries implementing a national salt reduction strategy more than doubled from 2010 to 2015 . However, despite the remarkable efforts and actions that have since been taken, more needs to be done. Data from 2013 revealed that population salt consumption in most European countries ranged from around $7 \mathrm{~g} /$ day (Bulgaria, Cyprus, Germany, and Latvia) to 13 g/day (Czech Republic) [7,8].

Among all dietary habits, excessive salt intake has the most adverse outcomes. The average daily intake of salt per capita among the Portuguese population is $10.7 \mathrm{~g}$ [9], which is double the level recommended by WHO $(<5 \mathrm{~g})$ [6]. Portugal ranks the highest among European countries regarding salt intake, with excessive intake reported in $63.2 \%$ of women and $88.9 \%$ of men [10]. The problem also affects younger groups, as research shows that most children and adolescents exceed daily recommendations [11-13].

Excessive salt intake is associated with an increased risk of obesity-partially due to poor diets that are high in both energy and salt, such as regular consumption of breakfast cereals [14] and highly processed foods [10]. Another reason for this association may be that consumption of salty foods stimulates thirst and increases fluid intake, thereby increasing the consumption of sugar-sweetened beverages, which can further fuel obesity [15]. This scenario is of particular interest in Portugal, where the prevalence of childhood overweight has been among the highest in Europe, affecting around one in three children [16]. It is, therefore, urgent to tackle this issue, as even small reductions in salt consumption can bring great health benefits to children by reducing the risk of developing cardiovascular diseases — the leading cause of death and disability in Portugal and worldwide [17,18].

The Portuguese "National Program for the Promotion of Healthy Eating" [19], in line with internationally recommended interventions [20], strongly advocates for the implementation of strategies to reduce dietary salt intake in children by providing information and education on healthy eating as well as the strengthening of consumer protections, particularly by reducing the salt content of school meals.

Several attempts have been made to reach children in schools to encourage healthier eating habits and improve the nutritional quality of the food served to them. These interventions can potentially impact all children of school age, irrespective of their ethnicity or socioeconomic group [21-25]. Primary and secondary schools serve at least one meal every day and can also determine the types of food and beverages that are available or served at schools (i.e., schools' cafeterias and vending machines). Schools can positively impact eating behaviors and promote healthier eating [26-28], for example, by deploying nutrition education classes.

School is a key setting to deliver health education to children, promote healthy lifestyles and social equality, and to ensure access to nutritionally balanced meals, regardless of the family's socioeconomic status [29]. In Portugal, municipalities are responsible for providing school meals (lunch) for pre-school and primary schools as well as for the management [30] of the menu. During secondary education, the supply of school meals is supported by the Directorate General of Education Institutions (DGEstE) [31], except for schools with their own cooking facilities. In Portugal, a set of guidelines for the school food supply has been established, which includes limits on the salt content of the school meal's components_-bread, soup, and the main dish [31]. 
Assuming that lunch represents $30 \%$ of the total energy value [32] and considering the WHO recommendation [6], $1.5 \mathrm{~g}$ of salt should be the maximum level in this meal. In Portugal, little is known about the nutritional composition of the complete school meal. The amount of different nutrients in food samples can be measured through laboratory analyses, using standardized techniques recommended by international organizations [33]. In the few studies that have been conducted to estimate sodium content of school meals in Portugal, mean salt content has ranged from 2.83 and 3.82 g [34-36], which clearly should be reduced.

Eat Mediterranean-A Program for Eliminating Dietary Inequalities in Schools (EM) [37], was a European Economic Area (EEA) Grant funded project developed as a Portuguese community-based intervention (2015 to 2017) through a multi-sectorial approach involving health, education, and political stakeholders. The program's goal was to reduce nutritional inequalities among school-aged children through the promotion of the Mediterranean diet. The program comprised a comprehensive approach both at the individual level (child and family) and at the group/community level (nutritional education sessions at schools and improvement of school food environments). One of the objectives and key priority areas in the implementation of EM at the community level was to evaluate and improve the nutritional quality of food available in school meals. Within the school food environment, the EM program proposed a qualitative and quantitative (laboratory) analysis and evaluation of the nutritional adequacy of school meals. The aim was to identify nutritional deviations, according to international/national recommendations $[29,31,38,39]$ and correct them by modifying the food composition of school meals through both training of the schools' food handlers and through the development and implementation of new menus.

\section{Materials and Methods}

\subsection{Program and Participant Schools}

The EM program was implemented over two school years (2015/2016 (Y1) to 2016/2017 (Y2)) in two Portuguese municipalities: Santarém and Alpiarça. In total, 25 individual public schools and 5773 students (3-21 years old), from pre-school to secondary education, participated in EM.

The entities responsible for the supply of school meals in both pre-schools and primary schools were Santarém Municipality (17 schools) and Alpiarça Municipality (three schools). For secondary schools, DGEstE supplied meals to four schools, while one had their own cooking service.

The specific evaluation and intervention on nutritional adequacy of served school meals (lunch) were organized in three phases:

- Evaluation (Y1): 386 school menus were analyzed qualitatively. Thirty-nine school meal samples were collected from 10 kitchens that served all 25 Schools for analysis during the period between March and June 2016. A report on qualitative and quantitative nutritional adequacy of school meals was presented to school communities.

- Intervention (Y1/Y2): From July 2016 to March 2017, a working group was established to discuss the results of the report from the evaluation phase and to develop a new proposal for school menus. The working group included public health professionals, nutritionists, a municipal food engineer, school cooks, teachers, and parents. The new school menus were developed according to the WHO recommendations $[29,38]$ and national guidelines [32,40], and these were implemented in all participant schools. Additionally, training was provided for the schools' food handlers in order to implement the new changes. During the intervention period, nutritionists from the working group closely followed and guided every step of the process, including food preparation, cooking and serving of the meals while, at the same time, providing training to the food handlers. The training covered topics, such as food safety, cooking methods, and portion guidance (for example, to estimate the amount of salt that could be added to food, a standard measuring spoon or cup was introduced for all food handlers to use). Additionally, technical 
sheets of the new menus were developed, and their implementation was conducted under the supervision of members of the working group.

- Post-intervention (Y2): A new set of 39 school meal samples was collected from the same kitchens from April to June 2017, and a qualitative and quantitative evaluation of the changes was performed.

Ethical approval was granted by Lisbon and Tagus Valley Regional Health Administration Ethical Committee (089.CES/INV/2015).

\subsection{Food Samples and Sample Preparation}

Food samples were collected from all 10 kitchens that served meals to the 25 schools. Of the 10 kitchens, nine served meals at their own schools, so samples were collected at the moment of serving. One school was served by transporting meals from a central kitchen outside the city. In this case, food samples were collected at the school immediately prior to serving.

The samples consisted of the food portions that were served to children at lunchtime. Each food sample consisted of three main items: bread, soup, and the main course (including salad or cooked vegetables and one piece of fruit). These were collected during both evaluation and post-intervention phases in a total of 39 samples in each phase. In one of the schools (school B), it was not possible to analyze the bread samples, as they were not sent to the laboratory. The meal items were weighed on a Mettler-Toledo PB3002-S/FACT (Mettler-Toledo, Inc., Columbus, OH) laboratory scale, with an accuracy of $0.01 \mathrm{~g}$. Samples were collected using latex gloves, placed in sterile polythene bags, and alphabetically coded to maintain confidentiality. The samples were transported to the laboratory, refrigerated, homogenized, and milled using a high-speed grinder, a knife mill Grindomix GM 200; Retsch, Haan, Germany equipped with titanium knives to prevent contamination. The prepared samples were stored in vacuum bags at the freezing temperature $\left(-20^{\circ} \mathrm{C}\right)$ until processing.

\subsection{Laboratory Analysis and Interpretation}

The analysis was performed in accordance with the methodology recommended by the Official Methods of Analysis of AOAC International [33], under quality assurance conditions complying with the requirements described in standard EN ISO/IEC 17025: 2005 [41]. For sodium determination, the samples were analyzed in triplicate using an inductively-coupled plasma optical emission spectrometer, ICP OES, model iCAP 6000, Thermo Fisher Scientific, Madison, WI, USA for the determination of sodium $(\mathrm{Na})$ content. There are several common sources of sodium in food, including from salt added during preparation or during processing, as well as from the sodium in seasoning (e.g., sodium phosphate, sodium bicarbonate, MSG mono-glutamate, etc.). However, this study assumed that all sodium in food was in the form of sodium chloride and equivalents, so all results were expressed in terms of "salt".

The salt content in $\mathrm{g} / 100 \mathrm{~g}$ of food was calculated by the formula: salt $(\mathrm{g})=$ sodium $(\mathrm{g}) \times 2.5$ [41]. Considering a school meal (lunch) makes up 30\% of the daily total energy intake [32], $1.5 \mathrm{~g}$ of salt was the reference value used in the present study (according to the WHO recommendation of salt intake [6]: $0.30 \times 5=1.5 \mathrm{~g})$.

\subsection{Statistical Analysis}

Data sets were produced using Microsoft Excel ${ }^{\circledR}$ spreadsheets, and statistical analyses were performed using IBM SPSS ${ }^{\circledR}$ statistics for Windows, version 22.0, Armonk, NY, USA [42]. Results were reported as mean (+ standard deviation). Non-parametric tests for comparing means were carried out for paired samples. A significance level of $\alpha=0.05$ was considered statistically significant.

\section{Results}

The quantitative analysis of the school menus found that the standardized serving portions collected during the evaluation phase and the post-intervention phase were similar. Regarding the reduction in 
sodium and salt equivalent of the individual meal components, there was a $34 \%$ reduction per serving portion of soup. There were no significant changes in sodium and salt equivalent per serving portion of bread or per serving portion of the main course. In the complete meal, including the three components, there was a $23 \%$ reduction in sodium and salt equivalent per serving portion (Table 1 ).

Table 1. Sodium and salt content of school meals components (soup, main course, and bread) and of the complete meal (all components) analyzed at the evaluation and the post-intervention phases of the eat Mediterranean program.

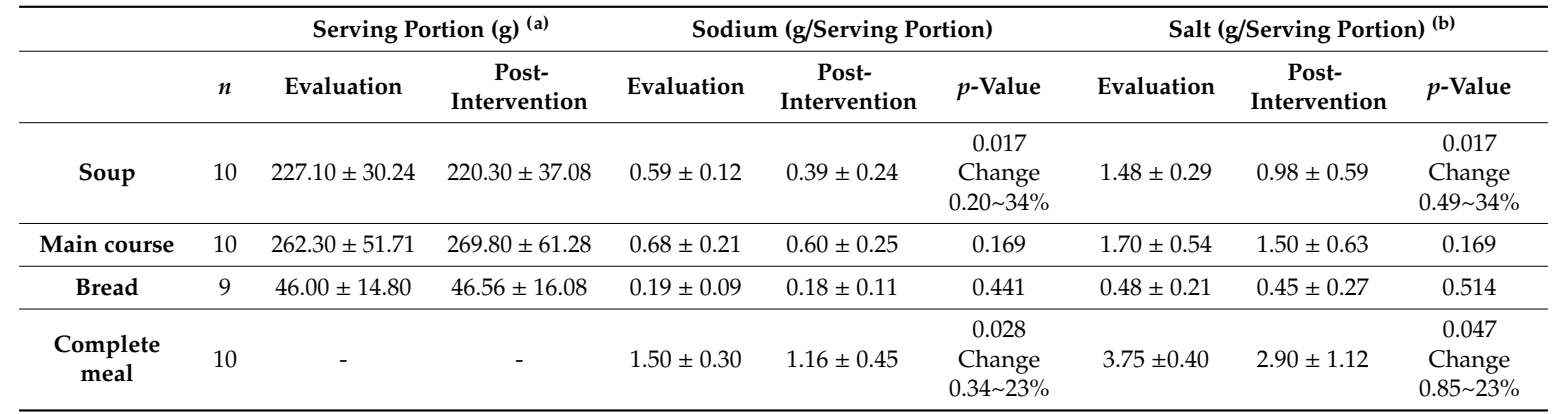

(a) There were no statistically significant differences between serving portions (g) $(p>0.05)$; ${ }^{\text {(b) }}$ The salt content was calculated by the formula: salt $(\mathrm{g})=\operatorname{sodium}(\mathrm{g}) \times 2.5[35]$.

Changes in the mean salt content of the complete school meal in grams $(\mathrm{g})$ at evaluation and at the post-intervention phase are shown, for individual schools and for all schools combined, in Figure 1. For all schools except for two ( $\mathrm{B}$ and J), there was a decrease in salt content between the two time-points.

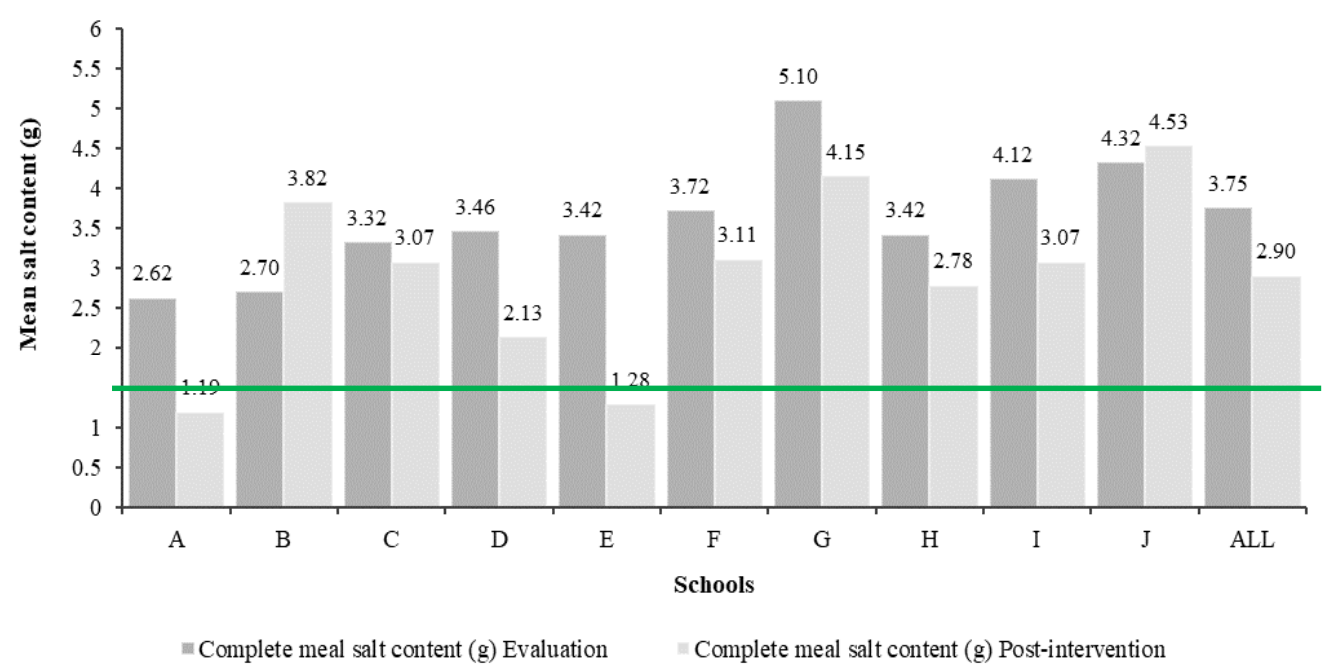

Figure 1. Mean salt content (g) of the complete school meals analyzed at the evaluation phase and the post-intervention phase of the eat Mediterranean program and its adequacy regarding the reference value (maximum $1.5 \mathrm{~g}$ of salt/meal), by the school.

\section{Discussion}

While community-based programs designed to improve the nutritional quality of school meals have been shown to be effective previously [43,44], EM was one of the first programs in Portugal to address qualitative and nutritional laboratory analysis together. Through a multidisciplinary approach targeting the school food environment, a key objective of the program was to improve the nutritional composition of school meals served to young people during lunchtime. In Portugal, addressing the quality of school meals is an important way to promote healthy diets as at least one meal is offered every day, and at pre- and primary education levels, almost every child has lunch at school [45]. 
The qualitative assessment of the 386 school menus has been presented elsewhere [46]. As part of evaluating EM, this study focused on identifying the nutritional deviations of sodium and salt equivalent content of school meals from international and national recommendations [29,31,38,39] and aimed to correct them by modifying the nutritional composition of school meals. This was done through training of the schools' food handlers and the development and implementation of new menus. The results showed that EM had a positive effect on the improvement of the school meals' salt content among the participating schools, achieving an overall reduction of $23 \%$ of the salt content of school meals served at lunchtime.

At the beginning of the EM program, the mean salt content of school meals was $3.75 \mathrm{~g}$ of salt per meal. These findings were similar to those reported in previous Portuguese studies [34-36], as well as in studies from other countries that assessed the salt content in school meals served in canteens [47]. Interventions as part of the EM program led to a significant reduction $(p<0.05)$ of salt content (from $3.75 \mathrm{~g}$ to $2.90 \mathrm{~g}$ of salt per meal, i.e., $\sim 23 \%$ ); however, it was still far from the reference value of lunch salt content (1.5 g of salt), and it was estimated that it would need to be met to achieve recommended salt consumption levels.

Looking separately at each component of the meal, the main dish was the component with the highest contribution to the salt content of the whole meal. This was also found in the study conducted by Barbosa et al. 2018 [48] in Portuguese University Canteens, in which it was suggested that one possible explanation for this result was the presence of intrinsic sodium in foods, such as meat and fish, which is higher than the sodium intrinsically present in vegetables used for soups [49]. However, we found a significant reduction in the salt content of soup from $1.48 \mathrm{~g}$ per serving portion before the intervention to $0.98 \mathrm{~g}$ per serving portion after the intervention ( $\sim 34 \%$ reduction).

The values for lunch salt content, after EM intervention, are yet slightly higher than those reported by other Portuguese studies [50,51]. According to the Portuguese 2018 guidelines for menus and school canteens [31], the maximum value that can be added to soups and main dishes during the cooking process is $0.2 \mathrm{~g}$ of iodized salt. In addition, it is recommended that salt be replaced by glasswort or aromatic herbs. Regarding the serving of bread included in the school meals, according to the recommendations for Portuguese school meals [31], it should be one small piece of bread of $25 \mathrm{~g}$ for pre-school and primary school and $45 \mathrm{~g}$ for elementary and secondary school, with a maximum salt composition of $1 \%$, meaning $0.25 \mathrm{~g}$ and $0.45 \mathrm{~g}$ of salt per serving of bread, respectively. As there was no intervention targeted at reducing bread provided during school meals, this study observed that, despite the level of education, the mean serving of bread was around $45 \mathrm{~g}$, and the salt content of bread per serving, both before and after the intervention, was above the guidelines $(0.46 \mathrm{~g}-0.49 \mathrm{~g})$. In Portugal, there is a culture of always serving bread at mealtime, which is reflected in the official guidelines [31]. It could be suggested that if there was a non-mandatory offer of bread at school meals, at least for young children, and if carbohydrate intake recommendations were met through foods with less salt, a further reduction on overall salt intake could have been observed through this action alone.

There were several challenges in the implementation of the EM program. One of these was to reduce the amount of salt added by cooks while preparing the meals, as while the technical guidance clearly requires that the amount of salt added during meal preparation be accurately measured, several cooks still opted to measure by "hand". This was also described by Gonçalves et al. [52], who found that the amount of added salt was influenced by the taste of the cook, even though many food handlers acknowledged that they did not taste the food before adding salt. That study also pointed out that food handlers were aware of the health problems associated with excessive salt intake as well as the recommended salt intake values, but they mentioned that the greatest difficulty in salt reduction was the opinion and acceptance of the consumers toward less salt in foods [52]. Such limitations reinforce the importance of educating both consumers and food handlers so that programs aiming at reducing the salt content in school meals and other settings can be more effective.

Action to reduce salt consumption is urgent, including among younger populations, in order to reduce the risk of developing cardiovascular diseases. The offer of high sodium meals in a school 
environment can contribute to individuals acquiring long-term poor eating habits, including increased consumption of processed food, which is already a pattern in Portuguese children [10]. Additionally, emerging evidence suggests dietary sodium intake may be associated with obesity, both through pathophysiological mechanisms and through the induction of thirst and increased consumption of high energy drinks [53-57], enhancing the need to address and tackle this public health issue.

The improvement of the menus introduced by the EM program has shown that it is possible to successfully reduce the salt content of school lunches through existing mechanisms. To ensure school meals are nutritionally adequate, it is essential that trained cooking staff and all responsible parties strictly comply with the technical sheets provided. It is also crucial to continue the education of students, parents, educators, teachers, as well as the monitoring of all stages of preparing and serving meals by the cooking staff. The integrated and concerted work among health departments, research institutions, municipalities, and educational communities was a strong part of the success of the EM program.

Among the common challenges educators face when trying to reduce the amount of added salt to meals is rejection by consumers due to "lack of flavor" [52]. However, the adaptive capacity of the flavors-linked neurological system to small reductions in salt in meals has been well described [57]. Thus, school settings may be ideal not only for nutrition literacy interventions among children but also for flavors, shaping and educating towards less salty food acceptance.

One of the pitfalls of this study was the limited time frame of the intervention to carry out all the activities projected in this comprehensive program without including a post-intervention longer monitoring period. This would have been important to continuously assess the adaptation to the changes implemented in the context of the new school food environment, in particular, the acceptance/preference of less salty meals by the children.

Nonetheless, recognizing the relevance of consumer acceptance in order to obtain long-lasting changes, EM paved the way for further work towards providing healthier meals in the participating schools, including a monitoring system to assess students' acceptance of school meals changes and also regarding food waste. The training, capacity building, and nutritional education offered during the EM intervention to all school community (teachers, parents, children, food handlers, and others) would hopefully contribute to the sustainability of the progress achieved in improvements and support continuous improvements.

\section{Conclusions}

This study demonstrated the success of the EM program in reducing the salt content of lunch meals served in schools. School meals must be nutritious, and reinforcement of this through regular monitoring and evaluation is a key factor to ensure school food quality. In order for school meals to be nutritionally adequate, trained cooking staff and all responsible parties would need to strictly comply with the provided technical sheets. It is crucial that the health literacy of students, parents, educators, and teachers is developed through continuous education, and the monitoring process at all stages of preparing and serving meals by school food handlers is strengthened. This comprehensive program was built through a collaboration between different stakeholders (health departments and units, research institutions, municipalities, and educational communities), which was both key to its success and ensured a holistic approach towards promoting healthier behaviors.

Author Contributions: The authors' contributions are as follows: A.I.R., was part of the coordinating team of eat Mediterranean and worked in all stages of the research, such as project design, methodology, analysis and interpretation of the data, and conceptualization, preparation and writing of the original manuscript; S.M. worked on the analysis and interpretation of the data; M.S. contributed to the laboratory analysis; A.D. (Ana Dinis) and C.R. coordinated and implemented the eat Mediterranean program, worked on the project design, data collection, and interpretation of the data. A.I.R.; S.M.; M.S.; F.G.-d.-S.; F.P.C.; S.W.; A.D. (Ana Dinis); C.R.; I.C.; A.D. (Ara Darzi); J.B. contributed to the writing, review and editing. All authors have read and agreed to the published version of the manuscript. 
Funding: The eat Mediterranean program (2015-2017) was coordinated by ARSLVT, Portugal, co-funded by the Public Health Initiatives Program (PT06) of the EEA Grants (grant application 171 NU2).

Acknowledgments: The authors wish to acknowledge all the nutritionists, psychologists, and other health professionals, children, parents, educators, teachers, school cooking staff, and municipality technicians for their contribution on the fieldwork, as well as the following Institutions for their partnership and support: Agrupamentos de Escolas Ginestal Machado, Sá da Bandeira e de José Relvas; Hospital Distrital de Santarém; CEIDSS-Centre for Studies and Research in Social Dynamics and Health; ISCTEIUL-Instituto Universitário de Lisboa; Municipalities of Alpiarça and Santarém and Instituto Nacional de Saúde Doutor Ricardo Jorge.

Conflicts of Interest: The authors declare no conflict of interest. The writing group takes sole responsibility for the content of this article, and the content of this article reflects the views of the authors only. S.W. and J.B. are staff members of the WHO. The WHO is not liable for any use that may be made of the information contained therein.

\section{References}

1. World Health Organization. Global Status Report on Noncommunicable Diseases 2014; World Health Organization: Geneva, Switzerland, 2014.

2. World Health Organization. Global Action Plan for the Prevention and Control of Noncommunicable Diseases 2013-2020; World Health Organization: Geneva, Switzerland, 2013.

3. Beaglehole, R.; Bonita, R.; Horton, R.; Adams, C.; Alleyne, G.; Asaria, P.; Baugh, V.; Bekedam, H.; Billo, N.E.; Casswell, S.; et al. Priority actions for the non-communicable disease crisis. Lancet 2011, 6736, 1438-1447. [CrossRef]

4. World Health Organization. Noncommunicable Diseases Progress Monitor, 2017; World Health Organization: Geneva, Switzerland, 2017; Available online: http://apps.who.int/iris/bitstream/10665/258940/1/9789241513029eng.pdf?ua=1 (accessed on 23 September 2019).

5. World Health Organization. Tackling NCDs: 'Best Buys' and Other Recommended Interventions for the Prevention and Control of Noncommunicable Diseases; World Health Organization: Geneva, Switzerland, 2017; Available online: https://apps.who.int/iris/handle/10665/259232 (accessed on 23 September 2019).

6. World Health Organization. Guideline: Sodium Intake for Adults and Children; World Health Organization: Geneva, Switzerland, 2012; Available online: https://www.who.int/publications/i/item/9789241504836 (accessed on 23 September 2019).

7. European Commission. Survey on Member Sates' Implementation of the EU Salt Reduction Framework; Publications Office of the European Union: Luxembourg, 2013; Available online: https://op.europa.eu/en/publicationdetail/-/publication/df7ef17e-d643-4593-94b3-84bacfa7a76a (accessed on 23 September 2019).

8. World Health Organization. Mapping Salt Reduction Initiatives in the WHO European Region; World Health Organization: Copenhagen, Denmark, 2013; Available online: http://www.euro.who.int/en/publications/ abstracts/mapping-salt-reduction-initiatives-in-the-who-european-region (accessed on 23 September 2019).

9. Polonia, J.; Martins, L.; Pinto, F.; Nazare, J. Prevalence, awareness, treatment and control of hypertension and salt intake in Portugal: Changes over a decade the PHYSA study. J. Hypertens. 2014, 32, 1211-1221. [CrossRef]

10. Lopes, C.; Torres, D.; Oliveira, A.; Severo, M.; Alarcao, V.; Guiomar, S.; Mota, J.; Teixeira, P.J.; Rodrigues, S.; Lobato, L.; et al. Inquérito Alimentar Nacional e de Atividade Física, IAN-AF 2015-2016: Relatório de resultados. Universidade do Porto, 2017. Available online: https://ian-af.up.pt/publicacoes (accessed on 26 September 2019).

11. Goncalves, C.; Abreu, S.; Padrao, P.; Pinho, O.; Graca, P.; Breda, J.; Santos, R.; Moreira, P. Sodium and potassium urinary excretion and dietary intake: A cross-sectional analysis in adolescents. Food Nutr. Res. 2016, 60. [CrossRef] [PubMed]

12. Correiacosta, L.; Cosme, D.; Nogueirasilva, L.; Morato, M.; Sousa, T.; Moura, C.; Mota, C.; Guerra, A.; Albinoteixeira, A.; Areias, J.C.; et al. Gender and obesity modify the impact of salt intake on blood pressure in children. Pediatric Nephrol. 2016, 31, 279-288. [CrossRef]

13. Sardinha, L.B.; Santos, D.A.; Silva, A.M.; Coelhoesilva, M.J.; Raimundo, A.; Moreira, H.; Santos, R.; Vale, S.; Baptista, F.; Mota, J. Prevalence of overweight, obesity, and abdominal obesity in a representative sample of Portuguese adults. PLOS ONE 2012, 7, e47883. [CrossRef] [PubMed] 
14. Rito, A.I.; Dinis, A.; Rascoa, C.; Maia, A.; Martins, I.D.; Santos, M.; Lima, J.; Mendes, S.; Padrao, J.; Steinnovais, C. Improving breakfast patterns of portuguese children-an evaluation of ready-to-eat cereals according to the European nutrient profile model. Eur. J. Clin. Nutr. 2019, 73, 465-473. [CrossRef] [PubMed]

15. Ma, Y.; He, F.; MacGregor, G. High Salt Intake_-Independent Risk Factor for Obesity? Hypertension 2015, 66, 843-849. [CrossRef] [PubMed]

16. Rito, A.I.; Cruz de Sousa, R.; Mendes, S.; Graça, P. Childhood Obesity Surveillance Initiative: COSI Portugal 2016; Instituto Nacional de Saúde Dr. Ricardo Jorge (INSA, IP): Lisbon, Portugal, 2017; Available online: http://hdl.handle.net/10400.18/4857 (accessed on 26 September 2019).

17. Programa Nacional para a Promoção da Alimentação Saudável. Portugal Alimentação Saudável em Números 2015; Direção-Geral da Saúde: Lisbon, Portugal, 2016; Available online: http://nutrimento.pt/activeapp/wp-content/ uploads/2016/03/Relatório-Portugal-Alimentação-Saudável-em-números-2015.pdf (accessed on 27 September 2019).

18. Li, X.; Jan, S.; Yan, L.L.; Hayes, A.J.; Chu, Y.; Wang, H.; Feng, X.; Niu, W.; He, F.J.; Ma, J.; et al. Cost and cost-effectiveness of a school-based education program to reduce salt intake in children and their families in China. PLOS ONE 2017, 12. [CrossRef]

19. Ministério da Saúde, Direção Geral da Saúde. Programa Nacional para a Promoção da Alimentação Saudável Orientações Programáticas; Direção-Geral da Saúde: Lisbon, Portugal, 2012; Available online: http://www.dgs. pt/programas-de-saude-prioritarios.aspx (accessed on 10 October 2019).

20. World Health Organization. The SHAKE Technical Package for Salt Reduction; World Health Organization: Geneva, Switzerland, 2016; Available online: https://apps.who.int/iris/rest/bitstreams/1061141/retrieve (accessed on 6 January 2020).

21. Lytle, L.A.; Kubik, M.Y. Nutritional issues for adolescents. Best Pract. Res. Clin. Endocrinol. Metab. 2003, 17, 177-189. [CrossRef]

22. World Health Organization. Diet, Nutrition and the Prevention of Chronic Diseases: Report of a Joint WHO/FAO Expert Consultation-Technical Report Series no. 916; World Health Organization: Geneva, Switzerland, 2003; Available online: https://apps.who.int/iris/bitstream/handle/10665/42665/WHO_TRS_916.pdf;jsessionid= EBC44FFF46A59BECE4352FE155FC349C? sequence=1 (accessed on 25 October 2019).

23. French, S.A.; Stables, G. Environmental interventions to promote vegetable and fruit consumption among youth in school settings. Prev. Med. 2003, 37, 593-610. [CrossRef]

24. Flodmark, C.E.; Marcus, C.; Britton, M. Interventions to prevent obesity in children and adolescents: A systematic literature review. Int. J. Obes. 2006, 30, 579-589. [CrossRef]

25. Sharma, M. International school-based interventions for preventing obesity in children. Obes. Rev. 2006, 8, 155-167. [CrossRef]

26. Centers for Disease Control and Prevention. Guidelines for school health programs to promote lifelong healthy eating. J. Sch. Health 1997, 67, 9-26. [CrossRef] [PubMed]

27. Branca, F.; Nikogosian, H.; Lobstein, T. The challenge of obesity in the WHO European Region and the Strategies for Response; World Health Organization: Copenhagen, Denmark, 2007; Available online: http://www.euro.who.int/en/publications/abstracts/challenge-of-obesity-in-the-who-europeanregion-and-the-strategies-for-response-the (accessed on 25 October 2019).

28. Commission of the European Communities. Green Paper-Promoting Healthy Diets and Physical Activity: A European Dimension for The Prevention of Overweight, Obesity and Chronic Diseases; European Commission: Brussels, Belgium, 2005; Available online: https://eur-lex.europa.eu/legal-content/EN/TXT/PDF/?uri=CELEX: 52005 DC0637\&from $=$ EN26 (accessed on 25 October 2019).

29. World Health Organization. Report of the Commission on Ending Childhood Obesity; World Health Organization: Geneva, Switzerland, 2016; Available online: https://www.who.int/end-childhood-obesity/final-report/en/ (accessed on 25 October 2019).

30. Ministério da Educação e da Ciência (2015) Parte C Despacho nº452-a/2015. Available online: https: //www.dgeste.mec.pt/wp-content/uploads/2014/01/Despacho8452A2015ASE.pdf (accessed on 25 October 2019).

31. Lima, R.M. Orientações sobre ementas e refeitórios escolares. Ministério da Educação-Direção-Geral da Educação. 2018. Available online: http://www.dge.mec.pt/sites/default/files/Esaude/oere.pdf (accessed on 13 November 2019).

32. Institute of Medicine (US) Committee on Nutrition Standards for National School Lunch and Breakfast Programs. School Meals: Building Blocks for Healthy Children; National Academies Press: Washington, DC, USA, 2010. 
33. Association of Official Analytical Chemists (AOAC). International Official Methods of Analysis of AOAC International; AOAC International: Rockville, MD, USA, 2000.

34. Paiva, I.; Pinto, C.; Queiros, L.; Meister, M.C.; Saraiva, M.; Bruno, P.; Antunes, D.; Afonso, M. Baixo valor calórico e elevado teor de sal. Acta Médica Portuguesa 2011, 24, 215-222. [PubMed]

35. Viegas, C.; Torgal, J.; Graça, P.; Martins, M. Evaluation of salt content in school meals. Rev. Nutr. 2015, 28, 165-174. [CrossRef]

36. Fontes, T.; Bento, A.; Matias, F.; Mota, C.; Nascimento, A.; Santiago, S.; Santos, M. O valor nutricional das refeições escolares. In Boletim Epidemiológico; INSA, IP N ${ }^{o}$ especial _ Alimentação e Nutrição: Lisboa, Portugal, 2015.

37. Eat Mediterranean Program. Available online: http://www.ceidss.com/eat-mediterranean/ (accessed on 10 December 2019).

38. World Health Organization. School Policy Framezork: Implementation of the WHO Global Strategy on Diet, Physical Activity and Health; World Health Organization: Geneva, Switzerland, 2008; Available online: http://www.who.int/dietphysicalactivity/SPF-En.pdf (accessed on 13 November 2019).

39. SPARE—Sistema de Planeamento e Avaliação de Refeições Escolares-Elaboração, Verificação e Monitorização na ótica do Utilizador. Available online: http://www.plataformacontraaobesidade.dgs.pt: 8080/SPARE2/index.php (accessed on 15 December 2019).

40. International Organization for Standardization. General Requirements for the Competence of Testing and Calibration Laboratories, 2nd ed.; ISO/IEC 17025:2005 (International Standard); International Organization for Standardization: Geneva, Switzerland, 2005.

41. Regulation (EU) No 1169/2011 of the European Parliament and of the Council of 25 October 2011 on the Provision of Food Information to Consumers; The Publications Office of the European Union: Luxembourg, 2011.

42. IBM Corp. IBM SPSS Statistics for Windows; Version 22.0; IBM Corp: Armonk, NY, USA, 2016.

43. Rocha, A.; Afonso, C.; Santos, M.C.; Morais, C.; Franchini, B.; Chilro, R. System of planning and evaluation of school meals. Public Health Nutr. 2014, 17, 1264-1270. [CrossRef]

44. Sancho, T.; Candeias, A.; Mendes, C.; Rego, M.; Cartaxo, L. Promoção da qualidade nutricional de refeições em estabelecimentos de educação do Algarve análise comparativa 2004/2005-2006/2007. Rev. Nutrícias 2008, 8, 1-3.

45. Rocha, A.; Ávila, H.; Barbosa, M. Caracterização da Prestação do Serviço de Refeições Escolares pelos Municípios Portugueses. Rev. Nutrícias 2012, 13, 3-8.

46. Rito, A.; Dinis, A.; Rascôa, C.; Rodrigues, S.; Stein-Novais, C.; Mendes, S.; Maia, A.; Luís, S.; Luciano, R. Nutrition Qualitative Evaluation and Improvement of School Meals in Portugal—Eat Mediterranean Program. Acta Port. Nutr. 2018, 12, 6-12. [CrossRef]

47. Ahn, S.; Park, S.; Kim, J.N.; Han, S.N.; Jeong, S.B.; Kim, H.K. Salt content of school meals and comparison of perception related to sodium intake in elementary, middle, and high schools. Nutr. Res. Pract. 2013, 7, $59-65$. [CrossRef]

48. Barbosa, M.; Fernandes, A.; Gonçalves, C.; Pena, M.; Padrão, P.; Pinho, O.; Moreira, P. Sodium and Potassium Content of Meals Served in University Canteens. Port. J. Public Health 2018, 35, 27-33. [CrossRef]

49. Martins, I.; Porto, A.; Oliveira, L. Tabela de Composição de Alimentos. In Departamento de Alimentação e Nutrição; Instituto Nacional de Saúde Doutor Ricardo Jorge: Lisbon, Portugal, 2007.

50. Gonçalves, C.; Silva, G.; Pinho, O.; Camelo, S.; Amaro, L.; Teixeira, V.; Padrão, P.; Moreira, P. Sodium content in vegetable soups prepared outside the home: Identifying the problem. In International Symposium on Occupational Safety and Hygiene: Book of Abstracts; Sociedade Portuguesa de Segurança e Higiene Ocupacionais: Guimarães, Portugal, 2012.

51. Goncalves, C.; Monteiro, S.; Padrao, P.; Rocha, A.; Abreu, S.; Pinho, O.; Moreira, P. Salt reduction in vegetable soup does not affect saltiness intensity and liking in the elderly and children. Food Nutr. Res. 2014, 58, 24825. [CrossRef] [PubMed]

52. Gonçalves, C.; Pinho, O.; Padrão, P.; Santos, C.; Abreu, S.; Moreira, P. Knowledge and practices related to added salt in meals by food handlers. Rev. Nutrícias 2014, 21, 14-17.

53. Libuda, L.; Kersting, M.; Alexy, U. Consumption of dietary salt measured by urinary sodium excretion and its associated with body weight status in healthy children and adolescents. Public Health Nutr. 2012, 15, 433-441. [CrossRef] [PubMed] 
54. Yoon, Y.S.; Oh, S.W. Sodium density and obesity; the Korea National Health and Nutrition Examination Survey 2007-2010. Eur. J. Clin. Nutr. 2013, 67, 141-146. [CrossRef] [PubMed]

55. Zhu, H.; Pollock, N.K.; Kotak, I.; Gutin, B.; Wang, X.; Bhagatwala, J.; Parikh, S.; Harshfield, G.A.; Dong, Y. Dietary sodium, adiposity, and inflammation in healthy adolescents. Pediatrics 2014, 133, e635-e642. [CrossRef]

56. Grimes, A.; Bolhuis, D.; He, F.; Nowson, C. Dietary sodium intake and overweight and obesity in children and adults: A protocol for a systematic review and meta-analysis. Syst. Rev. 2016, 5, 7. [CrossRef]

57. Cappuccio, F.P.; Capewell, S. Facts, issues and controversies in salt reduction for the prevention of cardiovascular disease. Funct. Food Rev. 2015, 7, 41-61. [CrossRef]

(C) 2020 by the authors. Licensee MDPI, Basel, Switzerland. This article is an open access article distributed under the terms and conditions of the Creative Commons Attribution (CC BY) license (http://creativecommons.org/licenses/by/4.0/). 